\title{
A new species of lotarphia Cameron (Coleoptera, Staphylinidae, Aleocharinae) from Tasmanian seacoasts, Australia
}

\author{
Seung-Gyu Lee', Andrew W. Osborn², Kee-Jeong Ahn³ \\ I Division of Forest Biodiversity, Korea National Arboretum, Pocheon 11186, South Korea 2 Honorary Re- \\ search Associate, Queen Victoria Museum and Art Gallery, 2 Invermay Road, Launceston, Tasmania 7250, \\ Australia 3 Department of Biology, Chungnam National University, Daejeon 34134, South Korea
}

Corresponding author: Kee-Jeong Ahn (kjahn@cnu.ac.kr)

Academic editor: A. Brunke | Received 27 September 2016 | Accepted 31 October 2016 | Published 16 November 2016

http://zoobank.org/AB4DD4D2-AD71-4A91-8206-A8D77914EEBD

Citation: Lee S-G, Osborn AW, Ahn K-J (2016) A new species of Iotarphia Cameron (Coleoptera, Staphylinidae, Aleocharinae) from Tasmanian seacoasts, Australia. ZooKeys 632: 67-74. doi: 10.3897/zookeys.632.10657

\begin{abstract}
Iotarphia rufobrunnea Lee \& Ahn, sp. n. is described from Tasmania. The new species is compared with another species of the genus, I. australis Cameron. A description, habitus photograph and illustrations of the diagnostic characters are provided.
\end{abstract}

\section{Keywords}

Coleoptera, Staphylinidae, Aleocharinae, Athetini, Iotarphia, new species, Tasmania

\section{Introduction}

While working on aleocharine beetles collected by the second author from the eastern and southern seashores in Tasmania, Australia, we found specimens very similar to the athetine genus Iotarphia Cameron. After detailed examination of the specimens and comparison with Iotarphia australis Cameron (type species of Iotarphia), we concluded that these specimens represent a new species of the genus. 
The athetine genus Iotarphia and its single described species have been recorded only in a "maritime habitat" from New South Wales and from Tasmania, both in Australia (Cameron 1943; Frank and Ahn 2011). Recently, Lee and Ahn (2015) synonymized the genus Psammopora Pace under Iotarphia. Little is known about their biology (Frank and Ahn 2011). In this paper, we provide a description, habitus photograph and line drawings of diagnostic characters of a new species of the genus Iotarphia.

\section{Method}

Descriptive terms used here follow Sawada (1972), but we followed Ashe (1984) in some cases, particularly for mouthparts, to reduce confusion.

\section{Results}

\section{Genus Iotarphia Cameron, 1943}

Iotarphia Cameron, 1943: 352. Type species: Iotarphia australis Cameron, 1943. Psammopora Pace, 2003: 154. Type species: Psammopora delittlei Pace, 2003.

Diagnosis. Members of Iotarphia are characterized by the combination of the following characters: labrum distinctly emarginate in anterior margin, with $\varepsilon$-sensillum conspicuously robust and blunt at apex; distal lobe of galea and lacinia developed, with many setae; ligula divided into two lobes; mentum emarginate in anterior margin; infraorbital carina absent; mesoventral process blunt at apex, reaching to half of mesocoxa; metaventral process narrow and pointed at apex; tarsal formula 4-5-5; metatarsi long (Pace 2003; Lee and Ahn 2015).

\section{Iotarphia rufobrunnea Lee \& Ahn, sp. n.}

http://zoobank.org/B2EABD60-7E6A-491D-834C-DD1520D42415

Figs 1-12

Material examined. Types. Tasmania. Holotype, male (QVM:2014:12:0119), Coal Point, Bruny Island, collected 25.ix.2014, A.W. Osborn. Paratypes: 4, of which 3 (QVM:2016:12:1052 to 1054) share common collection data with holotype, and 1 (QVM: 2014:12:0125) collected from Lighthouse Bay, Bruny Is., collected 24.ix.2014, A.W.Osborn.

All type specimens have been placed in the Queen Victoria Museum and Art Gallery, Launceston, Tasmania (QVMAG).

Description. Length 2.8-3.5 mm. Body (Fig. 1) subparallel-sided and reddish brown to reddish black; head and abdomen almost black, antennae and legs reddish 


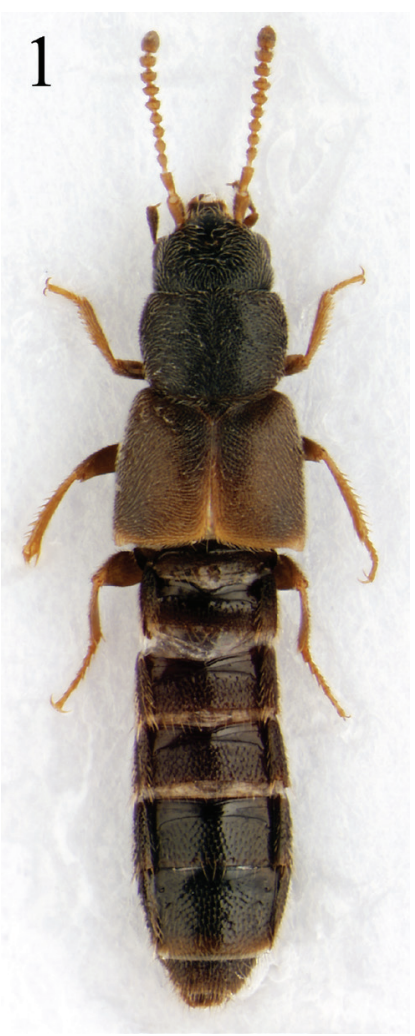

Figure I. Habitus of Iotarphia rufobrunnea sp. n., $3.4 \mathrm{~mm}$.

yellow, elytra reddish brown except for basal darker region; surface slightly glossy, densely pubescent with fine microsculpture. Head. Slightly transverse, approximately 1.1-1.2 times as wide as long, widest across eyes, narrower than pronotum; eyes slightly large and prominent, about 1.2 times as long as temples; gular sutures moderately separated, slightly diverged basally. Antennae (Fig. 7) slightly moniliform and about as long as head and pronotum combined; antennomeres 1-3 elongate, 1 longest, 2 distinctly longer than 3, 4-10 slightly to distinctly transverse, 11 longer than wide, slightly shorter preceding two combined. Mouthparts. Labrum (Fig. 2) with 8 macrosetae on each side of midline; epipharynx with several sensilla, including 2 lateral sensory rows on each side of midline; $\alpha$-sensillum setaceous, about as long as $\varepsilon$-sensillum; $\beta$ and $\gamma$-sensilla short. Mandibles (Fig. 3) slightly asymmetrical, subtriangular, decurved and narrow apically, about 1.6 times as long as basal width, with blunt internal tooth; prostheca developed, composed of three portions, many small denticles present in molar region. Galea and lacinia of maxilla (Fig. 4) moderately long and slender; lacinia composited of seven small spines in distal comb region, two isolated spines longer; maxillary palpus distinctly 4-articled, elongate and pubescent; palpomere 1 smallest, 2 about 2.5 times as long as wide, 3 slightly longer than 2, about 3.0-3.2 times as long as wide, 4 digitiform and relatively short, filamentous sensilla reaching to basal half. 


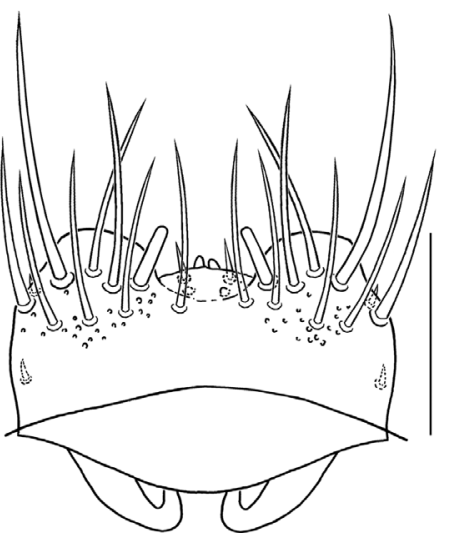

2

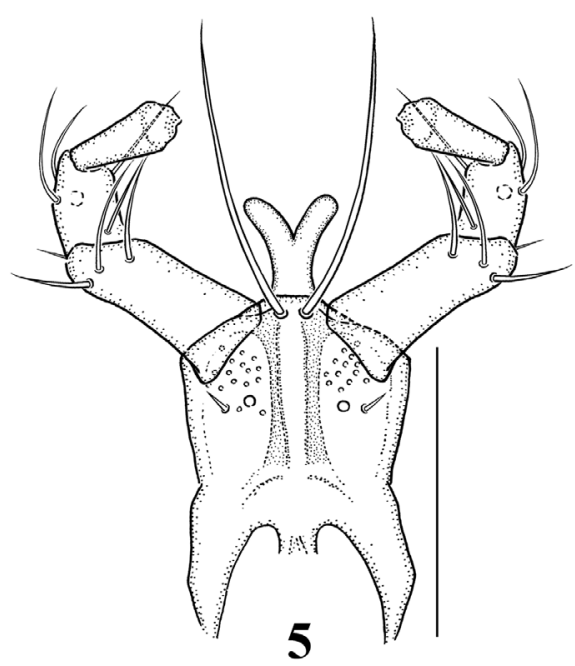

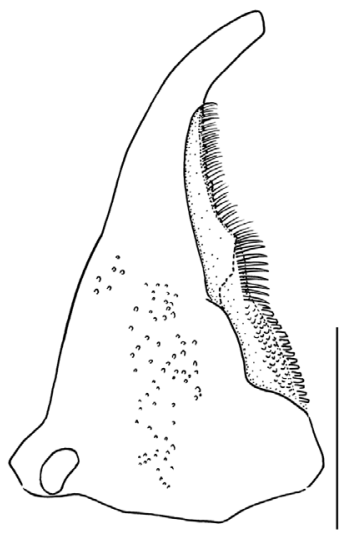

3

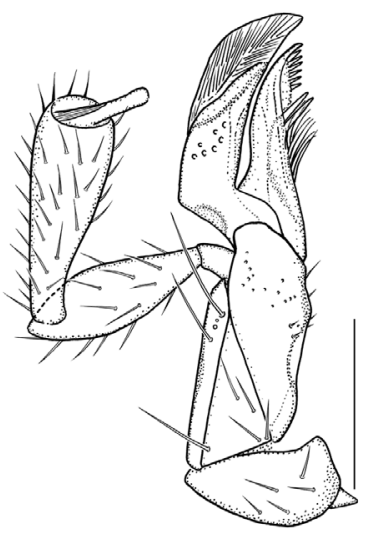

4

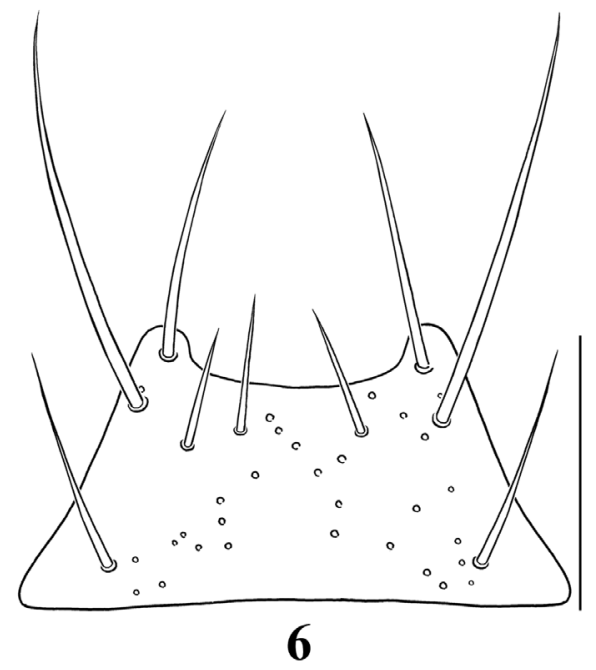

Figures 2-6. Mouthparts of Iotarphia rufobrunnea sp. n.: $\mathbf{2}$ labrum, dorsal aspect $\mathbf{3}$ right mandible, ventral aspect $\mathbf{4}$ right maxilla, ventral aspect $\mathbf{5}$ labium, ventral aspect $\mathbf{6}$ mentum, ventral aspect. Scale bars $=0.1 \mathrm{~mm}$.

Labium (Fig. 5) with ligula relatively broad and parallel-sided, divided into 2 lobes in basal half; medial pseudopore field of prementum very narrow, with several median pseudopores; two medial setae contiguous; two basal pores close together, one laterally behind the other; many lateral pseudopores, 1 setal pore and 1 real pore present on each side of midline; labial palpi 3-articled and elongate, with many setulae; palpomere 1 largest, about 2.0-2.5 times as long as wide, $\gamma$-setula slightly close to b-seta, 2 shortest, about 1.5-2.0 times as long as wide, 3 dilated apically and slightly shorter than 1 , about 2.0-2.5 times as long as wide. Mentum (Fig. 6) trapezoidal, anterior margin distinctly emarginate. Thorax. Pronotum transverse, approximately 1.3 times as wide as long, widest at apical third; pubescence directed anteriorly in midline; hypomera fully 

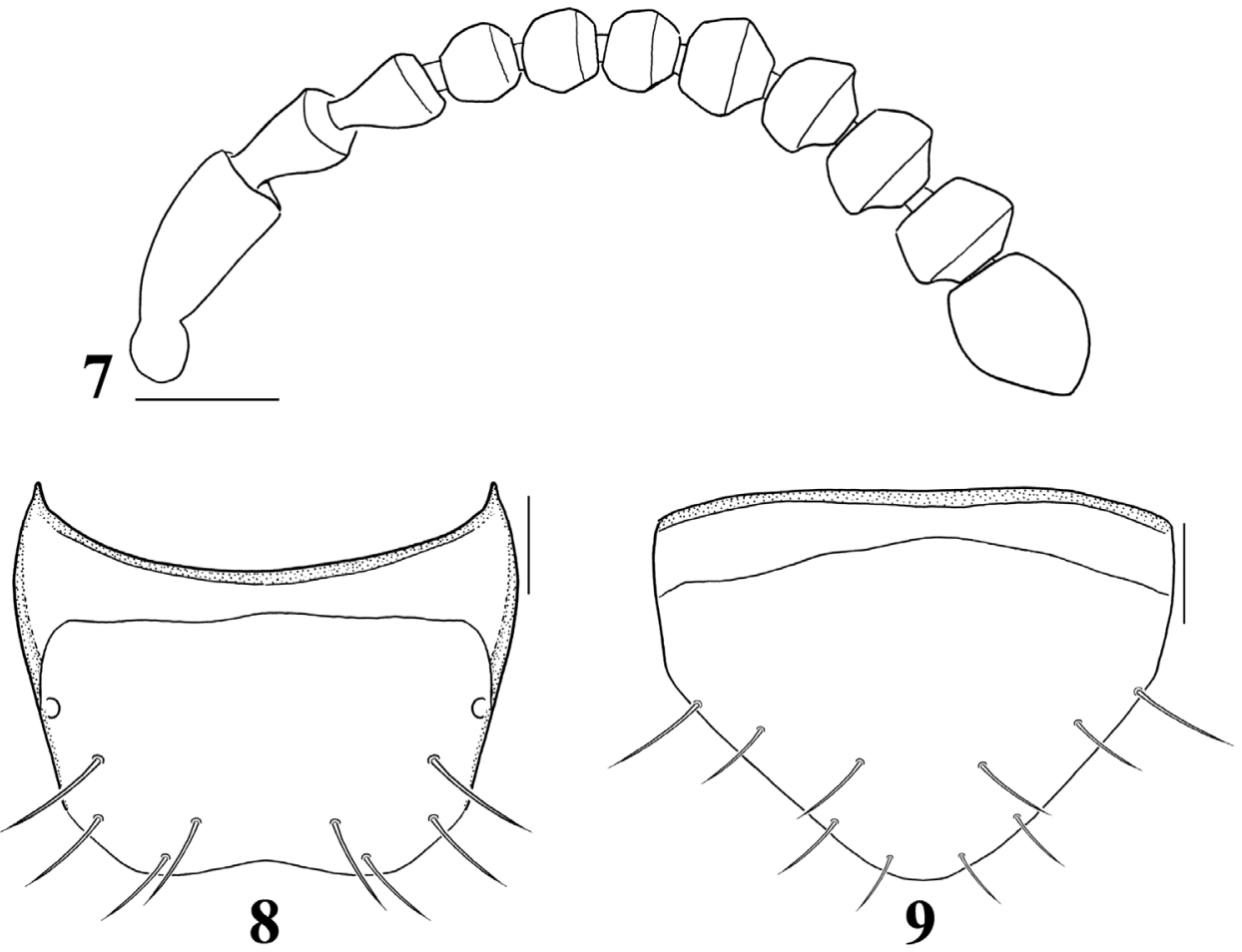

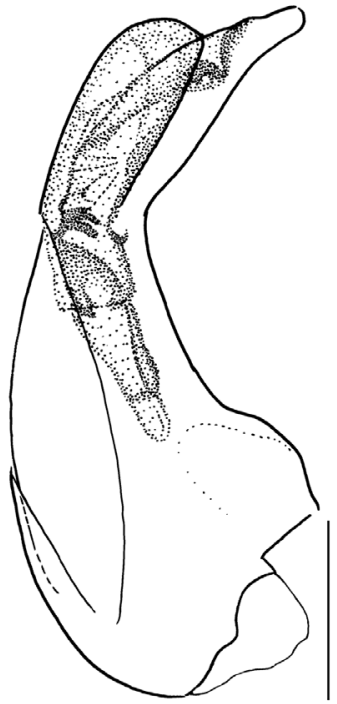

10

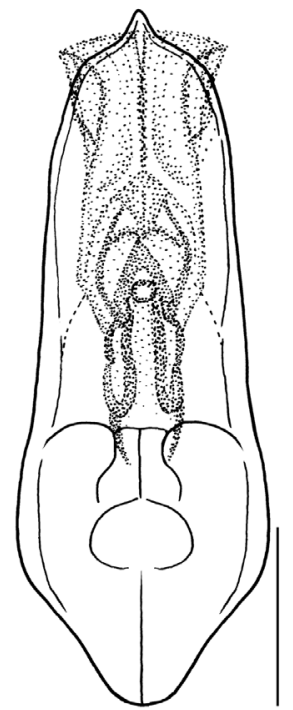

11

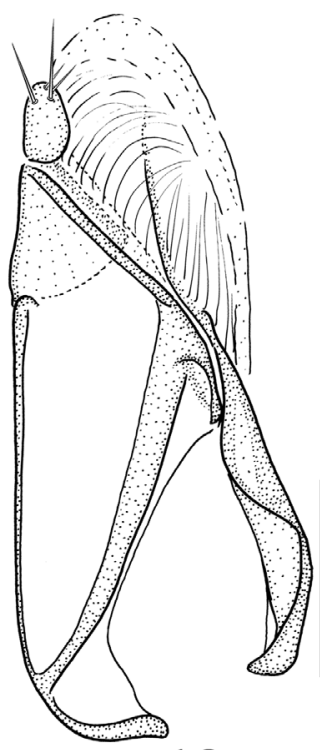

12

Figures 7-12. Diagnostic characters of Iotarphia rufobrunnea sp. n.: 7 antenna 8 male tergite VIII, dorsal aspect $\mathbf{9}$ male sternite VIII, ventral aspect $\mathbf{I} \mathbf{0}$ median lobe, lateral aspect $\mathbf{I} \mathbf{I}$ median lobe, ventral aspect $\mathbf{I} \mathbf{2}$ paramere, lateral aspect. Scale bars $=0.1 \mathrm{~mm}$. 


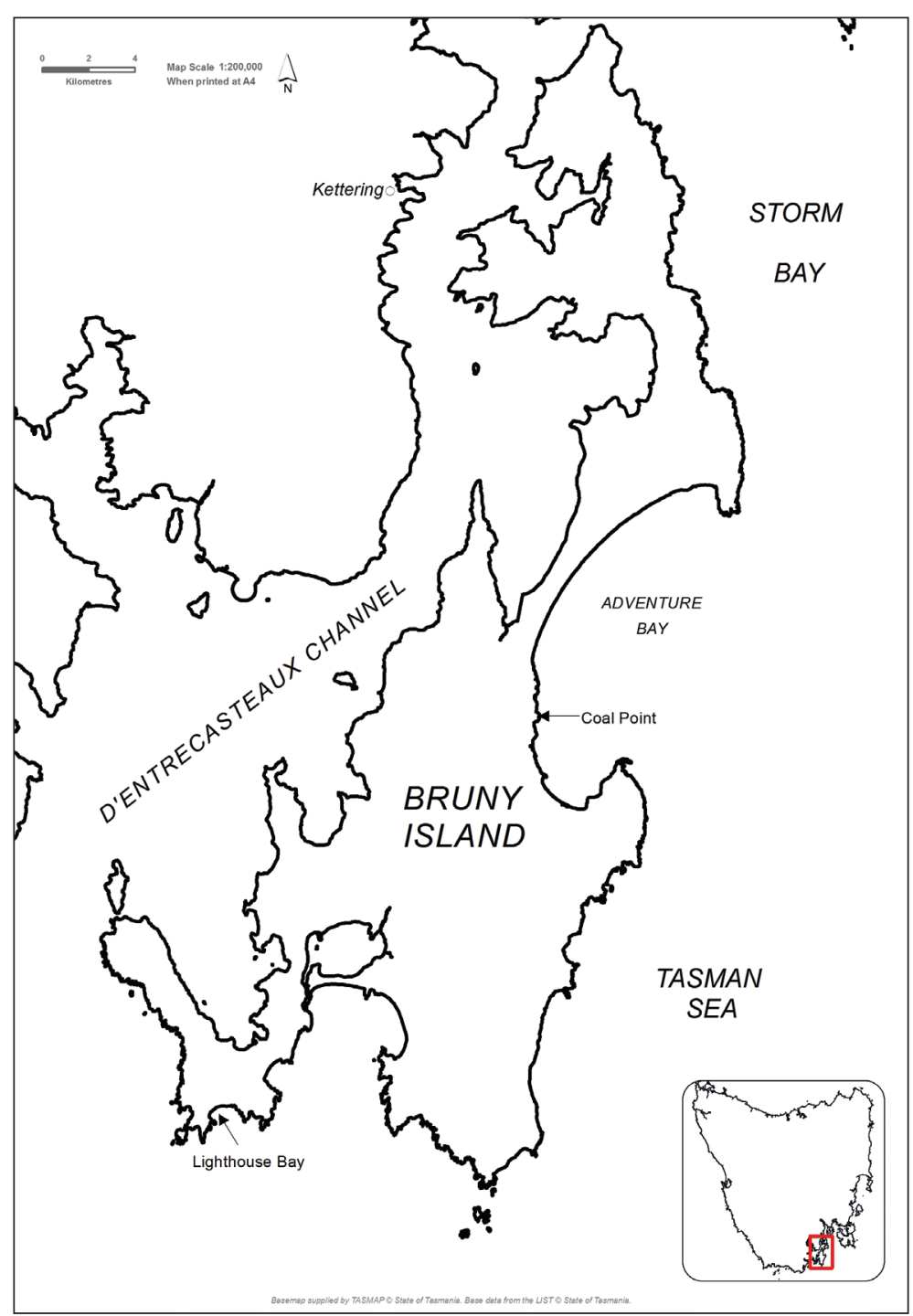

Figure 13. Distribution map.

visible in lateral aspect. Metanotal scutum with 1 long seta and about 3 short setae on each side of midline. Mesoventral process slightly longer than metaventral process, shorter than isthmus and metaventral process combined; isthmus slightly shorter than metaventral process. Metendosternite with distinctly elongate basal stalk and a pair of furcal arms. Elytra slightly longer and wider than pronotum; elytron approximately 1.6 times as long as wide, pubescence directed posteriorly and postero-laterally; postero-lateral margin almost straight; hind wings fully developed, flabellum composed of about 8 setose lobes. Legs. Moderately long and slender, with dense pubescence and macrosetae; pro- and mesotibiae with small and blunt spines along outer sur- 
Table I. Differences between I. australis Cameron and I. rufobrunnea sp. n.

\begin{tabular}{l|c|c}
\hline & I. australis & I. rufobrunnea sp. $\mathbf{n}$. \\
\hline Length & $2.2-3.0 \mathrm{~mm}$ & $2.8-3.5 \mathrm{~mm}$ \\
\hline Elytra color & yellow in most regions & reddish brown \\
\hline Antennomere 4 & about as wide as long & slightly transverse \\
\hline Mesoventral process & shorter than metaventral process & longer than metaventral process \\
\hline Meso- and metaventral processes & contiguous & separated \\
\hline
\end{tabular}

face; length ratio of tarsomeres 36:38:40:78 (protarsus); 40:43:46:48:78 (mesotarsus); 48:55:58:54:80 (metatarsus); one empodial seta present, shorter than claw. Abdomen. Subparallel-sided; surface glossy and densely pubescent, with transverse and imbricate microsculpture; male tergite VIII (Fig. 8) with 4 macrosetae on each side of midline, posterior margin slightly emarginate; male sternite VIII (Fig. 9) with about 5 macrosetae, posterior margin convex, long marginal setae present; Aedeagus. Median lobe (Figs 10-11) elongate oval, apical process elongate and convergent apically in ventral aspect, and slightly bent in lateral aspect. Apical lobe of paramerites (Fig. 12) narrow apically, with four setae; a-seta longest, b-seta longer than c-seta, d-seta shortest and close to c-seta and positioned at apex.

Etymology. Named from the Latin rufobrunnea meaning "reddish brown", which refers to the elytra color.

Distribution. Bruny Island, at both Lighthouse Bay and Coal Point (refer to map below), Tasmania, Australia (Fig. 13).

Remarks. This species is similar to I. australis, but can be distinguished by the characters provided in Table 1 and the shape and structure of the aedeagus. The specimens of the new species were collected on Bruny Island from (i) an entirely sandy substrate just into the supra-littoral zone at Coal Point (geographical coordinates: $43.34211^{\circ} \mathrm{S}$ and $147.32178^{\circ} \mathrm{E}$ ) and (ii) from a sandy substrate in which some small rocks were present within the littoral zone at Lighthouse Bay (geographical coordinates: $43.48616^{\circ} \mathrm{S}$ and $147.15022^{\circ} \mathrm{E}$ ).

The description of the new species within the present paper brings the total number of coastal Staphylinidae species in the Tasmanian fauna to five: Iotarphia australis (= Psammopora delittlei Pace), Iotarphia rufobrunnea Lee \& Ahn, sp. n., Teropalpus pictipes (Lea), Cafius pacificus (Erichson), and Remus sericeus (Holme).

\section{Acknowledgments}

We thank Roger Booth (NHM, London) and David Maynard (QVMAG, Tasmania, Australia) for arranging the loans of type specimens of Iotarphia australis and Psammopora delittlei (QVM:12:48278). We also are indebted to Judy Rainbird (Collections Officer QVMAG, Tasmania) for all aspects associated with processing the specimens of the new species, and thanks to Kathryn Pugh, QVMAG Honorary Research Associate, 
for GIS assistance. In addition we thank Bernard Edwards, Ranger and Scott Thornton, Field Officer, both of the Tasmanian Parks and Wildlife Service Bruny Island Field Centre, for permission to work on the island and to collect the specimens described herein. Finally, we express our sincere appreciation to the Plomley Foundation for awarding the research grant (to AWO) that supported the field work that subsequently led to the collection of the specimens described herein. This work was partially supported by Basic Science Research Program through the National Research Foundation of Korea (NRF) funded by the Ministry of Education, Science and Technology (2016R1D1A1B03930178).

\section{References}

Ashe JS (1984) Generic revision of the subtribe Gyrophaenina (Coleoptera: Staphylinidae: Aleocharinae) with a review of the described subgenera and major features of evolution. Quaestiones Entomologicae 20: 129-349.

Cameron M (1943) New species of Staphylinidae (Col.) from Australia and New Guinea. The Annals and Magazine of Natural History (series 11) 10: 336-354.

Frank JH, Ahn KJ (2011) Coastal Staphylinidae (Coleoptera): A worldwide checklist, biogeography and natural history. ZooKeys 107: 1-98. doi: 10.3897/zookeys.107.1651

Lee SG, Ahn KJ (2015) Psammopora Pace, a new synonym of Iotarphia Cameron (Coleoptera:

Staphylinidae: Aleocharinae). The Coleopterists Bulletin 53(3): 233-243.

Pace R (2003) New or little known Aleocharinae from the Australian Region (Coleoptera, Staphylinidae). Monografie del Museo regionale di Scienze naturali di Torino 35: 111-186. Sawada K (1972) Methodological Research in the Taxonomy of Aleocharinae. Contributions from the Biological Laboratory, Kyoto University 24: 31-59. 